\title{
UR Well Eye Care: a model for medical student ophthalmology education and service in the community
}

This article was published in the following Dove Press journal:

Clinical Ophthalmology

27 November 2014

Number of times this article has been viewed

\author{
Kyle MacLean' \\ Holly B Hindman ${ }^{2,3}$ \\ 'University of Rochester School \\ of Medicine and Dentistry, Rochester, \\ NY, USA $;{ }^{2}$ The Flaum Eye Institute, \\ University of Rochester, Rochester, \\ NY, USA $;{ }^{3}$ Center for Visual Science, \\ University of Rochester, Rochester, \\ NY, USA
}

Purpose: To assess medical student ophthalmic educational exposure and service provided through the University of Rochester's UR Well Eye Care (URWEC) program, a studentrun initiative in which medical students provide supervised eye care to an uninsured urban population.

Design: Retrospective chart review.

Subjects: Consecutive patients seen at the student-run URWEC in Rochester, NY, USA between June 2008 and June 2013.

Methods: One hundred and forty-five of 148 charts of consecutive patients seen at URWEC over the 5-year period were identified and reviewed. Data on patient demographics, reason for visit, history, examination, diagnoses, and management were collected into a database.

Main outcome measures: Main outcome measures included reasons for referral, student performance of ophthalmic examination components, ophthalmic diagnoses, and hours of volunteer service rendered.

Results: Patients came from a variety of countries and educational and racial backgrounds. The most common reason for referral to URWEC was diabetic screening eye exams $(66 / 145$, $46 \%$ ). Student volunteers performed the following examination components in $79 \%-100 \%$ of visits under direct supervision of an attending ophthalmologist: visual acuity, pupils, extraocular movements, confrontation visual fields, intraocular pressure, drop administration, slit-lamp examination, and dilated fundoscopic exam. The most common diagnosis other than refractive error was cataract $(29 / 145,20 \%)$. Almost half of patients $(66 / 145,46 \%)$ were diagnosed with potentially vision-threatening conditions. Six hundred and thirty hours of community service were rendered by students and attending ophthalmologists during the 5-year period.

Conclusion: Student-run eye clinics provide a longitudinal setting where students can receive one-on-one training with attending ophthalmologists, attain a broad clinical exposure, and provide a needed service in their communities.

Keywords: medical student education, student-run clinic, student-run eye clinic, volunteer eye clinic, ophthalmology education

\section{Introduction}

As the population in the US continues to age, it is expected that the prevalence of visual disabilities will significantly increase over the next several decades. ${ }^{1}$ It is reasonable to assume that this will increase the demand for eye care provided by both ophthalmologists and primary care physicians. Even with the implementation of the Affordable Care Act (ACA), many individuals requiring eye care will have no insurance. Yet, medical students are receiving less exposure to and training in ophthalmology. Only $30 \%$ of
Correspondence: Holly B Hindman

Flaum Eye Institute, University of

Rochester, 60I Elmwood Ave, Box 659,

Rochester, NY, USA

Tel +I 5852764629

Fax + I 5852760292

Email holly_hindman@urmc.rochester.edu 
medical schools have required ophthalmology rotations and many schools admit to not having a written ophthalmology curriculum. ${ }^{2}$ Student-run eye clinics may serve the two needs simultaneously - providing an opportunity to enhance ophthalmic clinical training of medical students and providing care for the underserved in our communities.

The number of student-run health clinics has grown over the past several years to well over 100 functioning throughout the US. According to the Society for Free Student-Run Clinics, which includes 138 registered clinics or programs, most of these clinics offer general or primary medical care. Some extend subspecialty services such as neurology, endocrinology, or homeless outreach as part of their clinic operations. Only eight medical schools have described a permanent, significant ophthalmology service or clinic in their clinic profiles. ${ }^{3}$ One of these is the University of Rochester's UR Well Health Outreach. One of the branches of this outreach effort is UR Well Eye Care (URWEC). Eye care is often underutilized by the uninsured and underserved communities. A study conducted by the Centers for Disease Control and Prevention found that lack of insurance and the cost of eye care were the most common reasons adults over 40 years with moderate-to-severe visual impairment did not seek eye care. ${ }^{4}$

In addition to providing needed eye care to our community members, URWEC also provides a unique environment for medical student ophthalmic education. Due to the minimal training of medical students in eye exam skills in the University of Rochester School of Medicine and Dentistry (URSMD) medical student curriculum, it is a concern that many students will graduate without having adequate training and confidence in recognizing common eye diseases. In 1995 , the vast majority of primary care residency directors in the US felt that the majority of their incoming residents had not acquired sufficient skills to adequately perform an ophthalmic screening examination. ${ }^{5}$ An intervention as simple as a 1-day ophthalmology training experience composed of anatomy, lecture, and physical exam practice has been shown to significantly increase the objective knowledge of eye care for medical students, as well as their confidence in performing exams. ${ }^{6}$ This model is currently practiced at the URSMD with an afternoon ophthalmology experience as part of the Primary Care Clerkship during the second year of the students' training. These skills, however, cannot be expected to be retained throughout 4 years of medical training and into residency. Examination skills for identifying eye disease acquired by medical students will be lost if not reinforced multiple times in a longitudinal fashion. ${ }^{7}$

\section{Methods}

Institutional Review Board approval was obtained to perform a retrospective chart review of all patients seen at URWEC. The data collection protocol was designed and performed in compliance with federal regulations (HIPAA). Using the clinic's scheduling system, 148 patients were identified that had been seen by URWEC over a 5-year period (2008-2013). Of those 148 patients, charts for 145 of the patients were identified and reviewed. Data was collected into a database from the 145 charts over a 4-week period in August 2013. Information taken from the charts included demographics (age, sex, race, education, income, marital status), reason for referral, past history, examination components performed, examination findings, diagnoses, treatment recommendations, and follow-up if noted.

\section{Results}

Patients seen through URWEC reported 19 different countries of origin, including the US. Fifty-two percent of patients were male (75/145), and $47 \%$ were female $(68 / 145)$. The mean age was 52 years old with a range of 24-80 years old. Thirty-six percent of patients self-identified as Black, $28 \%$ as non-Hispanic White, $19 \%$ as Hispanic, and $8 \%$ as Asian. Education levels varied from high school drop-out to completion of a Master's degree. Income levels ranged from $\$ 0 /$ month to $\$ 2,500 /$ month.

All patients were referred from the UR Well general health outreach or from other providers at the neighborhood clinic. The most common reasons for referral to URWEC were diabetic screening eye examinations (66/145, 46\%), decreased acuity or blurry vision $(28 / 145,19 \%)$, and routine vision screening $(8 / 145,6 \%)$. All reasons given for referral to URWEC are listed in Table 1.

In their assessments of the patients, medical students performed under direct observation, with immediate faculty feedback and reinforcement, the following skills: visual acuity $(145 / 145$ patients, $100 \%)$, pupils (126/145, 87\%), extraocular movements $(123 / 145,85 \%)$, confrontation visual fields $(114 / 145,79 \%)$, intraocular pressure $(113 / 125,90 \%)$, drop administration $(125 / 145,86 \%)$, slit-lamp examination $(125,86 \%)$, and dilated fundoscopic examination (125/145, $86 \%$ ). Students and attending ophthalmologists spent an estimated 630 hours volunteering at the clinic over the 5 years (two students and one attending ophthalmologist per clinic for an average of 3.5 hours per night, one clinic per month).

The most common diagnoses given to patients seen by URWEC were refractive error $(37 / 145,26 \%)$, cataract 
Table I Reasons for visit of patients seen at UR Well Eye Care from 2008 to 2013

\begin{tabular}{ll}
\hline Reason for appointment & Number of patients $(\mathbf{n}=\mathbf{1 4 5})$ \\
\hline Diabetic screening eye exam & 66 \\
Decreased vision/blurry vision & 28 \\
Routine vision screen & 8 \\
Glaucoma screen & 6 \\
Eye irritation/redness & 4 \\
Floaters & 4 \\
Hydroxychloroquine therapy & 3 \\
Headache & 2 \\
History of autoimmune disease & 2 \\
Eye discharge/watering & 2 \\
Eye twitch & $\mathrm{I}$ \\
Orbital trauma & $\mathrm{I}$ \\
Diplopia & $\mathrm{I}$ \\
Thyroid disease & $\mathrm{I}$ \\
Hypertension eye exam & $\mathrm{I}$ \\
Darkened vision & $\mathrm{I}$ \\
Photopsias & $\mathrm{I}$ \\
Photophobia & $\mathrm{I}$ \\
Postoperative follow-up &
\end{tabular}

Abbreviation: UR, University of Rochester.

(29/145, 20\%), glaucoma suspect $(15 / 145,10 \%)$, diabetic retinopathy $(11 / 145,8 \%)$ and dry eye $(11 / 45,8 \%)$. Other notable diagnoses included retinal detachment, maculopathy, optic neuritis, uveitis, and retinal embolus. All diagnoses given to patients at URWEC are listed in Table 2. Overall, $46 \%$ of patients had potentially vision-threatening diagnoses while $2 \%$ had potentially life-threatening diagnoses. The majority of patients were referred back to the URWEC clinic for follow-up care $(78 / 145,54 \%)$, while a smaller number were referred to the Flaum Eye Institute at the University of Rochester for advanced or surgical care (23/145, 16\%).

\section{Discussion}

Various methods or models have been proposed for providing lasting ophthalmic education to medical students. Some examples include an ophthalmic exam skills workshop during the second year with a reinforcing 4-day clerkship during the fourth year, plastic canisters as simulators for direct ophthalmoscopy, and using Internet-based assessments. ${ }^{7-9}$ One model that has not been addressed significantly in the literature is the student-run eye clinic as a longitudinal source of ophthalmic education. A recent study by Byrd et $\mathrm{al}^{10}$ found that students volunteering for training and at least 1 day of a service-based mobile eye clinic experience in the community demonstrated better ophthalmic knowledge and exam skills than classmates and internal medicine residents.

The student-run eye clinic provides a unique learning opportunity for a new generation of medical students. First,
Table 2 Diagnoses of patients seen at UR Well Eye Care from 2008 to 2013

\begin{tabular}{ll}
\hline Diagnosis & Number of patients $\mathbf{( n = 1 4 5 )}$ \\
\hline Refractive error & 37 \\
Cataract & 29 \\
Glaucoma suspect & 15 \\
Presbyopia & 15 \\
Nonproliferative diabetic retinopathy & II \\
Dry eyes & II \\
Dermatochalasis & 4 \\
Amblyopia & 3 \\
Macular disease & 3 \\
Retinal scar & 3 \\
Pterygium with cornea involvement & 3 \\
Peripheral vitreous detachment & 3 \\
Allergic conjunctivitis & 3 \\
Hypertensive retinopathy & 3 \\
Corneal lesion or scar & 3 \\
Retinal hole & 2 \\
Retinal detachment & 2 \\
Ptosis & 2 \\
Floppy eyelid syndrome & 2 \\
Optic neuritis & $\mathrm{I}$ \\
Traumatic aphakia & $\mathrm{I}$ \\
Restrictive strabismus & $\mathrm{I}$ \\
Retinal emboli & $\mathrm{I}$ \\
Asteroid hyalosis & $\mathrm{I}$ \\
Uveitis & $\mathrm{I}$ \\
Epiphora & $\mathrm{I}$ \\
Meibomitis & $\mathrm{I}$ \\
Chalazion & $\mathrm{I}$ \\
Tension headache & \\
Acne rosacea & \\
\hline
\end{tabular}

Abbreviation: UR, University of Rochester.

it offers a hands-on approach to learning where medical students can act as the main eye care provider for a patient (under the supervision of an attending ophthalmologist). Gaining confidence in clinical abilities is only achieved though clinical exposure, and cannot be correlated with simulation experience, tests scores, or clerkship grades. ${ }^{11}$ Changes in health systems are encouraging high-volume and high-efficiency eye clinics that provide less time for teaching. Providers may find that they have less and less time to teach students in their clinic if they are to keep up with their increasing patient loads. This is further complicated by the fact that medical students cannot simply jump in and participate in the more complex aspects of the eye exam. They must be trained on the anatomy, the disease processes, and how to use such tools as the slit lamp or indirect ophthalmoscope.

UR Well is an entirely student-led initiative. The leadership includes two clinic directors who oversee all operations and clinical coordinators who manage the outreach each night. There are also administrative coordinators, a 
fundraising committee, faculty recruitment, and other positions that are filled by medical students who have volunteered their time. UR Well has two weekly health outreach nights in partnership with two community organizations. The oldest of these partnerships is with St Joseph's Neighborhood Center (SJNC) in Rochester, NY, USA.

SJNC was established in 1993, as a ministry of the Sisters of St Joseph, in order to meet the growing needs of members of the community who are medically underserved. The center provides care for those who do not have medical insurance and who do not qualify for existing state or federal programs. UR Well has partnered with SJNC in order to expand their ability to provide care for the community's uninsured. UR Well volunteers staff the SJNC every Tuesday evening, providing extended hours and more appointments. URWEC has been operating since 2008, and supervised students provide ophthalmologic care to patients at the SJNC. Patients seen by URWEC have been referred from general providers that volunteer at SJNC or from the volunteer health teams that staff UR Well.

URWEC is now held twice every month (was previously once per month before June 2013) on a Tuesday night alongside the general UR Well Health Outreach at SJNC. It is staffed by an attending ophthalmologist, a senior medical student (with prior URWEC experience), and a junior medical student. URWEC runs year round, allowing up to 24 junior and 24 senior medical students to rotate through the clinic each year. SJNC has set aside two rooms for use by URWEC. One is an interview room with a table and chairs, and the other a fully equipped exam room with a projector and slit lamp donated to SJNC by community partners. Students obtain a history from the patient, and then take the lead in conducting a complete ophthalmologic exam with guidance from the attending physician. Most nights, the students work with 3-5 patients. They will receive one-on-one instruction from an attending ophthalmologist, including exam skills, writing notes, and developing a treatment and follow-up plan.

The dynamic between the senior medical student and the junior medical student also provides an opportunity for more experienced URWEC volunteers to teach the skills they have learned to students just beginning to learn the eye exam. The URWEC model truly allows students to follow the pattern of observing, practicing, and then teaching the eye exam. Peer-to-peer teaching provides a less stressful environment for the junior medical student and may even be more beneficial than learning from a resident. ${ }^{12}$ It also promotes collaboration, a key trait identified with the current generation of students classified as "millenials". ${ }^{13}$
One of the two major purposes of this study was to assess the educational and clinical exposure that medical students received while volunteering with URWEC. We found that students were exposed to a broad range of pathology, from simple cases of refractive error, to more complex and serious cases such as retinal detachment, maculopathy, or retinal embolus. Students saw numerous patients with the most common ophthalmic diseases, such as cataract, glaucoma, and diabetic retinopathy. Students were exposed to a diverse patient population; patients reported 19 different countries of origin, associated with unique cultural and genetic risk factors. In almost all of the patient encounters, students performed a comprehensive ophthalmic exam, including slit-lamp biomicroscopy and dilated fundoscopy. These findings support our conclusion that volunteer student-run clinics conducted over several nights at URWEC provide a comprehensive and intimate ophthalmology education for medical students.

Since the URWEC experience has been acclaimed by the students as an invaluable opportunity, our goal is to expand our current URWEC capabilities while also incorporating this instrumental training into the medical school curriculum. Opportunities being explored include developing a longitudinal Basic Ophthalmology Clerkship that would integrate evening lectures and skills sessions with ongoing patient care through URWEC. Instead of completing the clerkship over a short 1-week course, it could comprise several nights at URWEC. This would provide a longitudinal experience with reinforcement of knowledge, as well as more valuable faculty-student interactions than can often be obtained shadowing clinicians in their own busy clinics.

In addition to providing a unique educational opportunity for medical students, URWEC also provides a needed service to the community. Even in the setting of the changes under the ACA, there are many populations that will still lack access to eye care. Some notable populations are undocumented immigrants, naturalized citizens who have lived in the US for less than 5 years, and individuals who are exempt from filling federal tax returns due to low income. ${ }^{14}$ There are also many more that will assuredly choose to pay the penalty of the mandate portion of ACA over the cost of insurance. These patients come from diverse backgrounds and often lower socioeconomic populations.

Students and faculty provided care to 145 patients without insurance over 5 years (totaling 650 hours). More than half of these patients required follow-up care that was provided through URWEC. Sixteen percent of patients seen were referred for more advanced care or for surgical intervention. 
We have also noted that in reviewing the schedule for URWEC volunteer nights, regular appointments were filled several months in advance. These measures indicate the great need in the community for the eye care offered by URWEC.

The nature of the present study and outcomes measured limit the conclusions that can be definitively made. Our intention was to demonstrate that a student-run clinic can provide a comprehensive and longitudinal ophthalmic education, while also providing a needed service to underserved populations in our community. We believe this work will provide a foundation for further exploration of the utility of the student-run clinic as a tool in ophthalmology education of medical students. As stated earlier in this paper, over 100 student-run general clinics are functional across the country and could potentially provide an infrastructure in which to establish a student-run eye clinic. URWEC has also benefitted greatly from its partnerships with SJNC and the Flaum Eye Institute, which support this program by providing needed infrastructure and resources. Partnerships such as these are crucial for those looking to establish programs such as URWEC.

There are many opportunities for future investigations in medical student-run eye clinics including the retention of ophthalmic exam skills and knowledge in this or a similar program compared to students learning in traditional ophthalmology week-long electives, the experience of attending ophthalmologists who precept the clinics, patient satisfaction with care from student-run eye clinics, and cost-effectiveness of this model for medical student education and patient care relative to traditional means. Nonetheless, these preliminary results provide strong rationale for further exploration into the opportunities for student-run clinics to promote medical student education simultaneously with community health. True community building occurs as medical students donate their time and energy to caring for the underserved while the patients provide a service to the students by allowing them to hone their eye examination, diagnosis, and management skills.

\section{Acknowledgment}

The authors would like to thank Chris Wagner and the staff of St Joseph's Neighborhood Center for their support and assistance with data collection.

\section{Disclosure}

The authors report no conflicts of interest in this work.

\section{References}

1. Congdon N, O'Colmain B, Klaver CC, et al; Eye Diseases Prevalence Research Group. Causes and prevalence of visual impairment among adults in the United States. Arch Ophthalmol. 2004;122(4):477-485.

2. Shah M, Knoch D, Waxman E. The state of ophthalmology medical student education in the United States and Canada, 2012 through 2013. Ophthalmology. 2014;121(6):1160-1163.

3. Studentrunfreeclinics.org [homepage on the Internet]. Society of Student-Run Free Clinics. Clinical profiles. Available from: http:// www.studentrunfreeclinics.org/index.php?option=com_comprofiler \&task $=$ usersList\&listid=4. Accessed November 18, 2013.

4. Centers for Disease Control and Prevention (CDC). Reasons for not seeking eye care among adults aged $\geq 40$ years with moderate-to-severe visual impairment - 21 states, 2006-2009. MMWR Morb Mortal Wkly Rep. 2011;60(19):610-613.

5. Stern GA. Teaching ophthalmology to primary care physicians. The Association of University Professors of Ophthalmology Education Committee. Arch Ophthalmol. 1995;113(6):722-724.

6. Quillen DA, Cantore WA. Impact of a 1-day ophthalmology experience on medical students. Ophthalmology. 2006;113(12):2307-2309.

7. Lippa LM, Boker J, Duke A, Amin A. A novel 3-year longitudinal pilot study of medical students' acquisition and retention of screening eye examination skills. Ophthalmology. 2006;113(1):133-139.

8. Hoeg TB, Sheth BP, Bragg DS, Kivlin JD. Evaluation of a tool to teach medical students direct ophthalmoscopy. WMJ. 2009;108(1):24-26.

9. Asman P, Lindén C. Internet-based assessment of medical students' ophthalmoscopy skills. Acta Ophthalmol. 2010;88(8):854-857.

10. Byrd JM, Longmire MR, Syme NP, Murray-Krezan C, Rose L. A pilot study on providing ophthalmic training to medical students while initiating a sustainable eye care effort for the underserved. JAMA Ophthalmol. 2014;132(3):304-309.

11. Morgan PJ, Cleave-Hogg D. Comparison between medical students' experience, confidence and competence. Med Educ. 2002; 36(6):534-539.

12. Graziano SC. Randomized surgical training for medical students: resident versus peer-led teaching. Am J Obstet Gynecol. 2011;204(6):542. e1-e4.

13. Johanson L. Teaching the millennial generation: considerations for nurse educators. Nurse Educ. 2012;37(4):173-176.

14. Gohel N, Patel V, Rahiman R. ACA's impact on free and charitable clinics. The Bulletin: Journal of the Monroe County Medical Society. 2013;79(3):20-21.
Clinical Ophthalmology

\section{Publish your work in this journal}

Clinical Ophthalmology is an international, peer-reviewed journal covering all subspecialties within ophthalmology. Key topics include: Optometry; Visual science; Pharmacology and drug therapy in eye diseases; Basic Sciences; Primary and Secondary eye care; Patient Safety and Quality of Care Improvements. This journal is indexed on

Submit your manuscript here: http://www.dovepress.com/clinical-ophthalmology-journal

\section{Dovepress}

PubMed Central and CAS, and is the official journal of The Society of Clinical Ophthalmology (SCO). The manuscript management system is completely online and includes a very quick and fair peer-review system, which is all easy to use. Visit http://www.dovepress.com/ testimonials.php to read real quotes from published authors. 